\title{
Characterization on antioxidant and physical properties of gelatin based composite films with incorporation of Centella asiatica (pegaga) extract
}

\author{
Nazmi, N.N.M. and *Sarbon, N.M. \\ School of Food Science and Technology, Universiti Malaysia Terengganu, 21030 Kuala Nerus, \\ Terengganu, Malaysia
}

\begin{abstract}
Article history:
Received: 2 July 2019

Received in revised form: 3 August 2019

Accepted: 6 August 2019 Available Online: 26 August 2019
\end{abstract}

\section{Keywords:}

Centella asiatica extract,

Gelatin films,

Carboxymethyl cellulose

(CMC),

Chicken skin gelatin,

Active packaging

\section{DOI:}

https://doi.org/10.26656/fr.2017.4(1).243

\begin{abstract}
This study aimed to characterize the influence of Centella asiatica at $0.3 \%$ and $0.7 \%$ on antioxidant activities; mechanical and physical properties of chicken skin gelatin/CMC/ Centella asiatica film. Characterization of the blended films with $0.7 \%$ Centella asiatica extract shows higher antioxidant activities with a total phenolic content of $0.36 \mathrm{mg} / \mathrm{g}$ of GAE, DPPH of $89.26 \%$, and reducing power of $0.80 \mathrm{~nm}$ compared to $0.3 \%$ Centella asiatica extract added where the total phenolic content was $0.29 \mathrm{mg} / \mathrm{g}$ of GAE, DPPH of $89.26 \%$ and reducing power of $0.80 \mathrm{~nm}$. The addition of $0.3 \%$ of Centella extract provide higher value in tensile strength, elongation at break, melting point and transparency but lower in UV-light penetration and crystallinity of the films. While the addition of $0.7 \%$ Centella extract contributes to higher value in WVP and puncture test. In conclusion, the incorporation of Centella asiatica extracts on film greatly increased antioxidant levels and improved some of the mechanical and physical properties of the film blends.
\end{abstract}

\section{Introduction}

In recent years, there has been an increased demand for food packaging that offers an improved shelf life for food products. The most common quality loss in packaged foods is caused by oxidation (Hong and Krochta, 2006). Oxidative processes cause the degradation of meat proteins, pigments, and lipids, limiting shelf life (Liu et al., 2010). Hence, active packaging may carry antioxidants to delay the deleterious effect (Yingyuad et al., 2006).

Currently, many researchers are focusing on packaging films with antioxidant agents from natural sources as alternatives to synthetic antioxidants such as grape seed extract (Moradi et al., 2012), Zataria multiflora Boiss essential oil (Moradi et al., 2012), green tea extract (Siripatrawan and Harte, 2010), carvacrol (López-mata et al., 2013). In many kinds of natural extract, Centella asiatica contains several active ingredients such as asiaticoside, histidine, brahmoside, brahmonoside, madecassoside, lysine, alanine madecassic acid, riboflavin, threonine, serine, pyridoxine, glutamate, asparate, and vitamin K (Singh et al., 2014). In addition to these active ingredients, it also contains volatile oils such as farnesol and caryophyllene; and also flavonoids such as quercetin, apigenin, catechin, kaempherol and naringin that contribute the high total phenolic contents. Incorporation of antioxidant compounds into films will provide protection to food product from oxidation, enzymatic browning, microorganism's growth, and vitamin losses (SilvaWeiss et al., 2013).

Biodegradable films are generally based on lipids, proteins, and polysaccharides. Previously, studies have shown that one of protein source material that getting high interest nowadays in order to form a packaging and film was gelatin. The use of gelatin in the preparation of edible films or coating has been well studied (Nor et al., 2017; Suderman and Sarbon, 2019). However, several safety concerns and religious issues concerning commercial gelatin (Jridi et al., 2014) have led to the exploration of different alternative substitutes of raw materials for production of gelatin, such as chicken skin (Sarbon et al., 2013) and fish skin (Cheow et al., 2007; Rosli and Sarbon, 2015).

Studies proved that biodegradable films formed by merging selected biopolymers have improvedthe homogeneous structure and better physicochemical properties compared to the films with mono component (Qi et al., 2015). Many researchers on properties of blended film have been conducted such as gelatinchitosan blended film, cassava starch-wax blended film (Chiumarelli and Hubinger, 2014) and gelatin- soy protein isolate (Cao et al., 2007). Carboxymethyl cellulose (CMC) is a substitute polymer with excellent 
stability, viscosity, availability and biocompatibility and preferably used to blend with gelatin. The addition of $\mathrm{CMC}$ to the gelatin based films increases molecular aggregates and modulus of elasticity between gelatin and CMC (Nazmi et al., 2017). Previously, the study on the effect of plasticizer concentration on chicken skin gelatin film characterization has been conducted successfully by Nor et al. (2017). However, there is still limited study of the antioxidant and properties of film from chicken skin gelatin/CMC blended film incorporated with Centella asiatica extract. Therefore, this study aimed to investigate the effect of different Centella asiatica extract levels on antioxidant, mechanical, physical and thermal properties of chicken skin gelatin/CMC blended film as a primary food packaging.

\section{Materials and methods}

\subsection{Materials}

Chicken skin for gelatin production was purchased at TD Poultry Sdn. Bhd. Kuala Terengganu, Malaysia. The fresh Centella asiatica was purchased from a local market in Kuala Terengganu, Malaysia. Carboxymethyl cellulose was purchased from Sigma-Aldrich Company Ltd., United Kingdom. All other chemicals used in this study were of analytical grade.

\subsection{Methods}

\subsubsection{Sample preparation}

The chicken skins were kept on ice during transport to the laboratory. The visible fat on the skin was removed and rinsed in excessive water in order to remove the impurities. The skin then was oven dried at $55^{\circ} \mathrm{C}$ for $24 \mathrm{hrs}$ and ground, then defatted following by Soxhlet method (AOAC, 2006).

\subsubsection{Gelatin extraction}

Chicken skin gelatin was prepared following the technique as described by Sarbon et al. (2013) using acid -alkaline pretreatment. The defatted ground chicken skin was soaked in $0.15 \%(\mathrm{w} / \mathrm{v})$ of sodium hydroxide, $0.15 \%$ $(\mathrm{w} / \mathrm{v})$ of sulphuric acid and acid $0.7 \%(\mathrm{w} / \mathrm{v})$ of citric solution serially. Each soaking treatment with a total time of 2 hrs was repeated three times. Final wash of the skin with distilled water was done in order to remove any residual matter. The solution mixture was extracted in distilled water in water bath at a controlled temperature $\left(45^{\circ} \mathrm{C}\right)$ for overnight. The clear extract which is gelatin in solution form was filtered, concentrated by evaporation under low pressure, and freeze-dried to form a gelatin powder.

\subsubsection{Preparation of Centella asiatica extract}

The Centella asiatica extract was prepared following the method used by Reihani and Azhar (2012). The Centella asiatica leaves and barks were washed using cleaned water, freeze-dried and ground. Approximately $10 \mathrm{~g}$ of dried Centella asiatica were weighted and then mixed uniformly in a beaker with $100 \mathrm{~mL}$ boiled water for 10 mins using magnetic stirrer. Then, the extracts were filtered with $125 \mathrm{~mm}$ filter papers, concentrated by evaporation under low pressure, and freeze-dried. The extraction powder then was kept in a chiller $\left(4^{\circ} \mathrm{C}\right)$ before being used.

\subsubsection{Development of chicken skin gelatin films}

Gelatin film was produced using the casting technique as described by Jahit et al. (2016). To prepare film-forming solution (FFS), $3 \mathrm{~g}$ of chicken skin gelatin was dispersed in $50 \mathrm{ml}$ distilled water while $3 \mathrm{~g}$ of CMC was dispersed in $50 \mathrm{~mL}$ distilled water separately. Both solutions then were mixed together, and then $0.78 \mathrm{~mL}$ of glycerol were added as plasticizer. Next, Centella asiatica extract was added to the chicken skin gelatin/ $\mathrm{CMC}$ solution. The following three solutions were prepared: (i) control, without Centella asiatica extract; (ii) with $0.3 \%$ Centella asiatica extract; and (iii) with $0.7 \%$ Centella asiatica extract. The solutions were heated on the heating mantle with continuous stirring at $45 \pm 5^{\circ} \mathrm{C}$ for $60 \pm 5$ mins and kept for 5 mins in room condition. A total of $50 \mathrm{~g}$ of the solutions in the beakers then were poured onto container in order to control film thickness. They were dried at oven at $45^{\circ} \mathrm{C}$ until completely dry.

\subsection{Antioxidant properties}

\subsubsection{Total Phenolic content}

The total phenolic contents of the blended films were determined with Foline Ciocalteu reagent per Suderman and Sarbon (2019). About $25 \mathrm{mg}$ of each film sample was dissolved in $5 \mathrm{~mL}$ of distilled water. Approximately $0.5 \mathrm{~mL}$ Folin-Ciocalteu reagent and $7 \mathrm{~mL}$ distilled water were mixed with $0.1 \mathrm{~mL}$ of the extract solution in the test tube, and stored for 8 mins at room temperature. Next, $1.5 \mathrm{~mL}$ distilled water and sodium carbonate $(2 \%, \mathrm{w} / \mathrm{v})$ was added into the same test tube to obtain a final volume of $10 \mathrm{~mL}$. The mixture then was stirred and keeps at room temperature for $2 \mathrm{hrs}$. Then, absorbance reading of sample mixture at $765 \mathrm{~nm}$ against water on a UV spectrophotometer was being taken. The following equation was used to express the results in terms of $\mathrm{mg}$ gallic acid equivalents (GAE $\mathrm{mg} / \mathrm{g}$ ) per gram of dried film:

Total phenolic content $(\mathrm{mg} / \mathrm{g}$ of GAE $)=(\mathrm{CV}) / \mathrm{M}$

Where $\mathrm{C}$ is the concentration of gallic acid obtained from the standard calibration curve $(\mathrm{mg} / \mathrm{mL}), \mathrm{V}$ is the volume of film extract ( $\mathrm{ml})$, and $\mathrm{M}$ is the weight of dried 
film $(\mathrm{g})$.

\subsubsection{DPPH radical - scavenging activity}

DPPH test on blended films was conducted following method by Razali et al. (2015). Approximately $25 \mathrm{mg}$ of each films sample was dissolved and continuous stir in $5 \mathrm{~mL}$ of distilled water. About $3.9 \mathrm{~mL}$ of the DPPH solution ( $0.1 \mathrm{mM}$ in methanol solution) was mixed with $0.1 \mathrm{~mL}$ of extract solution, followed by 60 mins incubation room temperature in dark area. The absorbance was measured at $517 \mathrm{~nm}$ against pure methanol and the percentage of DPPH radicalscavenging activity was calculated using the following equation:

DPPH Radical Scavenging Activity $(\%)=\frac{A_{\text {blank }}-A_{\text {sample }}}{A_{\text {blank }}} \times 100$

Where $\mathrm{A}$ is absorbance at $517 \mathrm{~nm}$; $\mathrm{A}_{\text {blank }}$ is absorbance of blank sample which DPPH solution $(0.1 \mathrm{mM}$ in methanol solution); and $\mathrm{A}_{\text {sample }}$ is absorbance of film sample with different extracts concentrations.

\subsubsection{Reducing power}

The reducing power was performed according to the method described by Razali et al. (2015) with slight modification. Approximately $1.0 \mathrm{~mL}$ of sample or the control sample was mixed with $2.5 \mathrm{~mL}$ of $10 \mathrm{mg} / \mathrm{mg}$ potassium ferricyanide and $2.5 \mathrm{~mL}$ of $0.2 \mathrm{M}$ phosphate buffer (pH 6.6), prior with incubation for 20 mins at $50^{\circ}$ C. The solution then was centrifuged. About $0.5 \mathrm{~mL}$ of $0.1 \%$ ferric chloride, $2.5 \mathrm{~mL}$ deionized water and $2.5 \mathrm{~mL}$ of supernatant was mixed together. The absorbance at $700 \mathrm{~nm}$ was measured after a 10 mins reaction. A higher reducing power indicated by the higher absorbance.

\subsection{Mechanical and physical properties of film}

2.4.1 Tensile strength (TS) and elongation at break (EAB)

Tensile strength (TS) and elongation at break (EAB) of the film were determined by using a texture analyser (TA.TX Plus, Stable Micro System, UK) following methods described by Nur Hazirah et al. (2016). A film strip with a measurement of $20 \mathrm{~mm} \times 100 \mathrm{~mm}$ was prepared by using a cutting blade. The film was then placed onto grip pairs of AT/G probe which was attached to the texture analyzer with $10 \mathrm{~kg}$ load cell. The initial gap of $60 \mathrm{~mm}$ between the up and down parts of the grip was set. The strip was stretched by the moving at headspace of $100 \mathrm{~mm} / \mathrm{min}$ until broken. The TS (MPa) was calculated using the following equation:

$$
\text { Tensile Strength }(\mathrm{MPa})=\frac{\mathrm{F}_{\max }(\mathrm{N})}{\mathrm{A}_{\left(\mathrm{m}^{2}\right)}}
$$

Where $F_{\max }$ is max load $(\mathrm{N})$ needed to pull the sample apart; and A is cross-sectional area $\left(\mathrm{mm}^{2}\right)$ of film sample.

Meanwhile, the elongation at break (EAB) was calculated as follows:

$$
\operatorname{EAB}(\%)=\frac{l_{\max }}{l_{0}} \times 100
$$

Where $l_{\max }$ is the film elongation (mm) at the moment of rupture; and $l_{o}$ is the initial grip length $(\mathrm{mm})$ of sample.

\subsubsection{Puncture strength}

The deformation and strength of the films at the breaking point were determined by puncture test. The test was evaluated using an Instron model 4501 Universal Testing Machine (Instron Co., Canton, MA, USA) instrument. The films were placed in a $5.6 \mathrm{~cm}$ in diameter of probe cell. The film was perforated to the breaking point using round-ended stainless-steel plunger $2 \mathrm{~mm}$ in diameter, at a crosshead speed of $1 \mathrm{~mm} / \mathrm{s}$ and a $50 \mathrm{~N}$ load cell. Breaking strength was expressed in terms of $\mathrm{N}$ and breaking deformation as a percentage, as previously described by Nur Hazirah et al. (2016). All determinations were the means of at least three measurements.

\subsubsection{Water vapour permeability (WVP)}

Water vapour permeability (WVP) was measured by using a modified ASTM method as described by Jahit et al. (2016). The films were sealed onto a cup containing silica gel $(0 \% \mathrm{RH})$ with silicone vacuum grease and a rubber band to hold the films in place. The cups with films were then weighted as initial weight. The cups then placed in desiccators containing distilled water at $30^{\circ} \mathrm{C}$. The cups were weighted at $1 \mathrm{hr}$ intervals over $7 \mathrm{hrs}$ of period. Three films were used for WVP determination and the measurement was conducted in triplicate. WVP of the film was calculated as follows:

$$
\operatorname{WVP}\left(\mathrm{g} \mathrm{m}^{-1} \mathrm{~s}^{-1} \mathrm{~Pa}^{-1}\right)=\mathrm{wxA}^{-1} \mathrm{t}^{-1} \Delta \mathrm{Pa}^{-1}
$$

Where $\mathrm{w}$ is the weight gain of the cup $(\mathrm{g})$; $\mathrm{x}$ is the film thickness (m); $\mathrm{A}$ is the exposed area of film $\left(\mathrm{m}^{2}\right)$; $\mathrm{t}$ is the time of gain (s); and $\Delta \mathrm{Pa}^{-1}$ is the vapor pressure difference across the film $(\mathrm{Pa})$

\subsubsection{Thermal properties}

The measurement of melting temperature of the film was carried out following the method described by Rosli and Sarbon (2015), with some modifications, using a differential scanning calorimetry (DSC Q2000 Modulated, TA Instrument, USA) equipped with a cooling device (Intercooler II) supported by a Pyris Thermal Analysing System. About $5 \mathrm{mg}$ of films were weighed using the Metler Toledo precision balance (AL 204, Metler-Toledo Ltd., Beaumont Leys Leicester, UK) 
and then enclosed in air-tight aluminum pans. The reference was an empty pan sealed with a lid to give a suitable heat capacity. These were analyzed at a heating rate of $10^{\circ} \mathrm{C} / \mathrm{min}$ ranging from $0-175^{\circ} \mathrm{C}$. The temperature at which one-half of the gelatin film denatured was taken as the top of the peak. The total energy required for denaturing the film (the enthalpy change, $\Delta \mathrm{H}$ ) was measured by integrating the area under the peak. The endothermic peak was selected as the melting temperature for gelatin film and an average reading was taken from three replications.

\subsubsection{Film light transmission and transparency}

The visible and ultraviolet (UV) light barrier properties of the films were measured using a UV-1700 UV-Visible double beam spectrophotometer (Shimadzu, Kyoto, Japan) following the procedure reported by Jahit et al. (2016). Film size of $1 \mathrm{~cm} \times 2 \mathrm{~cm}$ was prepared and placed directly into the test cell, with a reference by empty test cell. The absorbance (\%) against visible and UV light at selected wavelengths $(400,600,800 \mathrm{~nm})$ were measured. Film transparency was calculated as follows:

\section{Transparency $=-\log \mathrm{T} / x$}

Where $\mathrm{T}$ is transmission (\%) at $600 \mathrm{~nm}$ and $x$ is film thickness $(\mathrm{mm})$. Film thickness was measured using Digimatic Micrometer (Mitutoyo, Japan) using the method reported by Li et al. (2014). All determinations were recorded as the mean of three measurements.

\subsubsection{Microstructure using scanning electron microscopy (SEM)}

The scanning electron microscopy (Nova Nano SEM 230, FEI, USA), was used to examine the morphology of the film, per Li et al. (2014). Film specimens (2 mm x 2 $\mathrm{mm}$ ) were fractured by dipping in liquid nitrogen for 2 mins and attached on copper stubs upright to their surface. Samples were gold coated using an accelerating voltage of $30 \mathrm{KV}$. Samples were observed using magnification from $500-1500$.

\subsubsection{X-Ray diffraction (XRD)}

X-ray pattern of chicken skin gelatin/CMC/Centella asiatica blended film was analysed using Rigaku X-Ray Diffractometer following a method according to Nur Hazirah et al. (2016) with some modifications. The sample was mounted on $2 \times 2$ " glass slide and was secured on the X-ray platform by using tape. This analysis was run with $\mathrm{Cu} \mathrm{Ka}$ radiation at a current of 30 $\mathrm{mA}$ and voltage of $40 \mathrm{kV}$. The sample then was scanned between $2 \Theta=3^{\circ}$ to $80^{\circ}$ with a scanning time 30 mins per running. The tests were conducted in triplicate.

\subsection{Statistical analysis}

For statistical analysis, one-way ANOVA variance analysis was performed by Minitab 14.0 software and comparisons of means utilized Tukey's test at a confidence level of $p<0.05$. Each analysis was calculated in triplicate.

\section{Results and discussion}

\subsection{Total Phenolic content}

Total phenolic contents of chicken skin gelatin/CMC film incorporated with different concentration of Centella asiatica extract and chicken skin gelatin/CMC film (control film) are presents in Table 1. The total phenolic content values were increased as the concentration of Centella asiatica extract in the films increases. Centella asiatica incorporated in gelatin/CMC blended film showed higher TP content compared to control films. Chicken skin gelatin film without extract (control film) also showed some antioxidant activity. This may be due to the contribution by amino acid composition of chicken skin gelatin. Chicken gelatin was reported to have high proline, hydroxyproline, glycine in amino acid (Sarbon et al., 2013). Moreover, it also may be due to the reaction of Folin and Ciocalteu reagent with non-phenolic reducing substances and caused the formation of chromogens, which can be detected spectrophotometrically (Siripatrawan and Harte, 2010). Chicken skin gelatin/CMC blended films incorporated with $0.7 \%$ Centella asiatica extract, possessed higher TP content $(0.36 \mathrm{mg} / \mathrm{g}$ of GAE) 6 times greater than the control film $(0.06 \mathrm{mg} / \mathrm{g}$ of GAE). The total phenolic content in the produced film was related to the total phenolic content in the Centella asiatica extract showed a strong relationship between the phenolic compound and the antioxidative activity. The phenolic compounds are active hydrogen donors, making them a good antioxidant. The phenolic compounds might be responsible for the oxidative activities of Centella asiatica including phenol and flavonoids (Singh et al., 2014).

Table 1. Radical Scavenging DPPH activity and reducing power of chicken skin gelatin/CMC film incorporated with different concentration of Centella asiatica extract and chicken skin gelatin film/CMC (control film)

\begin{tabular}{cccc}
\hline $\begin{array}{c}\text { Film } \\
\text { Formulations }\end{array}$ & $\begin{array}{c}\text { DPPH } \\
(\%)\end{array}$ & $\begin{array}{c}\text { Reducing } \\
\text { Power } \\
(\mathrm{nm})\end{array}$ & $\begin{array}{c}\text { Total phenolic } \\
\text { compound } \\
(\mathrm{ml} / \mathrm{g} \text { of GAE })\end{array}$ \\
\hline Control & $41.95 \pm 1.96^{\mathrm{c}}$ & $0.48 \pm 0.01^{\mathrm{c}}$ & $0.06 \pm 0.01^{\mathrm{c}}$ \\
$0.3 \%$ extract & $68.88 \pm 0.84^{\mathrm{b}}$ & $0.66 \pm 0.01^{\mathrm{b}}$ & $0.29 \pm 0.01^{\mathrm{b}}$ \\
$0.7 \%$ extract & $89.26 \pm 1.25^{\mathrm{a}}$ & $0.80 \pm 0.02^{\mathrm{a}}$ & $0.36 \pm 0.01^{\mathrm{a}}$ \\
\hline
\end{tabular}

Different superscript within a column with different letters indicate significant difference $(p<0.05)$ 


\subsection{Antioxidant properties}

\subsubsection{DPPH radical scavenging activity}

Data on antioxidant activities of chicken skin gelatin film (control) and chicken skin gelatin/CMC film incorporated with Centella asiatica extract are shown in Table 1 . The DPPH values of blended films with $0.7 \%$ extract added were significantly $(\mathrm{p}<0.05)$ higher as compared to blended film with $0.3 \%$ extract added and control film. The results show that the addition of C.asiatica extract into gelatin based film possessed higher scavenging activity on DPPH radical. The antioxidant activities of the C.asiactica plant are mainly due to phenolic compounds including flavonoids, phenolic acid, and tannins (Zainol et al., 2003). These phenolic compounds can interrelate with protein through chemical cross-linking interaction. Phenolic compounds are significant to antioxidant because their redox potentials will able them to act as a metal chelator, reducing agents, singlet oxygen quenchers and hydrogen donor (Chew et al., 2011). The compounds usually interact via covalent interactions. The covalent interaction between protein and phenolic compounds occur through oxidation of phenolic compounds to radicals (Simpson et al., 2012). With antioxidant properties, the film with the addition of antioxidant might provide benefits as packaging able to delay or inhibit oxidation (EÇA et al., 2014). The addition of Centella asiatica extract will give antioxidant properties to chicken skin gelatin/CMC blended film by reducing the DPPH radical activity (Suderman and Sarbon, 2019).

\subsubsection{Reducing power}

Similar to the DPPH radical scavenging activity, films blended with Centella asiatica extract showed higher value in reducing power compared to the control (without extract), as shown in Table 1. The increased in the concentration of Centella asiatica extract significantly increased reducing power $(p<0.05)$. The ability to reduce ferric ion $\left(\mathrm{Fe}^{3+}\right)$ of the blended film with $0.7 \%$ Centella asiatica extract added was higher than blended films with $0.3 \%$ Centella asiatica extract added and control films $(p<0.05)$. This was similar to the finding by Moradi et al. (2012), which found that chitosan film's reducing power value was increased by adding grape seed extract and Zataria multiflora Boiss essential oil. The amount of added antioxidant additives generally is proportional to the degree of the antioxidant power of edible film. This blended film incorporated with Centella asiatica extract can play a role of an electron or hydrogen donors, which could terminate the radical chain reaction by reacting with free radicals and convert them to more stable products (Suderman and Sarbon, 2019).

\subsection{Mechanical and physical properties}

\subsubsection{Tensile strength (TS) and elongation at break (EAB)}

The tensile strength (TS) of chicken skin gelatin film (control) and chicken skin gelatin/CMC film incorporated with Centella asiatica extract are shown in Table 2. Films Incorporated with Centella asiatica extract were significantly $(p<0.05)$ higher in tensile strength as compared to control film. The increased film tensile strength with Centella asiatica extract added is attributed to the polyphenolic compounds which contain many hydrophobic groups, which can form hydrophobic interaction with the hydrophobic region of gelatin molecules. Hydrogen acceptors of gelatin molecule able to combine with Hydroxyl groups of polyphenolic compounds via hydrogen bonds (Hoque et al., 2011). Furthermore, Centella asiatica contained a lot of polyphenolic compounds. Because of that, Centella asiatica via hydrophobic interaction and hydrogen bonds could interact with gelatin thus leading to film strengthening (Rasid et al., 2018). Polyphenol-protein interactions had improved mechanical properties of gelatin films through incorporation with cinnamon extracts (Hoque et al., 2011).

The elongation at break (EAB) of chicken skin gelatin film (control) and chicken skin gelatin/CMC film incorporated with Centella asiatica extract are shown in Table 2. The EAB for blended films fused with $0.3 \%$ Centella asiatica extract was increased from $223.05 \%$ to $281 \%$. However, the EAB was apparently reduced to $271.17 \%$ when the concentration of $0.7 \%$ Centella asiatica extract was added. The EAB is reflected in the flexibility of the film. The higher elongation values at breaking point may be related to flexibility. Increase in

Table 2. Tensile strength, elongation at break, puncture test, water vapor permeability, melting point and glass transition of chicken skin gelatin/CMC film incorporated with different concentration of Centella asiatica extract and chicken skin gelatin film/CMC (control film)

\begin{tabular}{ccccccc}
\hline Film formulations & $\begin{array}{c}\text { Tensile strength } \\
(\mathrm{MPa})\end{array}$ & $\begin{array}{c}\text { EAB } \\
(\%)\end{array}$ & $\begin{array}{c}\text { Puncture Test } \\
(\mathrm{N})\end{array}$ & $\begin{array}{c}\text { WVP } \times 10^{-4} \\
\left(\mathrm{~g} \mathrm{~m}^{-1} \mathrm{~s}^{-1} \mathrm{~Pa}^{-1}\right)\end{array}$ & $\begin{array}{c}\mathrm{T}_{\mathrm{m}} \\
\left({ }^{\circ} \mathrm{C}\right)\end{array}$ & $\begin{array}{c}\Delta \mathrm{H} \\
(\mathrm{j} / \mathrm{g})\end{array}$ \\
\hline Control & $3.0 \times 10^{-2} \pm 0.01^{\mathrm{b}}$ & $223.05 \pm 3.84^{\mathrm{c}}$ & $0.06 \pm 0.0^{\mathrm{a}}$ & $1.03 \pm 0.00^{\mathrm{a}}$ & $124.38^{\mathrm{c}}$ & $0.10 \pm 0.01^{\mathrm{c}}$ \\
$0.3 \%$ extract & $5.0 \times 10^{-2} \pm 0.00^{\mathrm{a}}$ & $281.00 \pm 0.00^{\mathrm{a}}$ & $0.05 \pm 0.0^{\mathrm{a}}$ & $1.11 \pm 0.00^{\mathrm{a}}$ & $131.31^{\mathrm{a}}$ & $0.63 \pm 0.00^{\mathrm{b}}$ \\
$0.7 \%$ extract & $4.5 \times 10^{-2} \pm 0.00^{\mathrm{a}}$ & $271.17 \pm 2.12^{\mathrm{b}}$ & $0.06 \pm 0.08^{\mathrm{a}}$ & $1.13 \pm 0.00^{\mathrm{a}}$ & $130.11^{\mathrm{b}}$ & $1.26 \pm 0.01^{\mathrm{a}}$ \\
\hline
\end{tabular}

Different superscript within a column with different letters indicate significant difference $(p<0.05)$ 
concentration of extract might cause an increase in pore sizes of the films and creating possible rapture points, thus leads to decreased of EAB (Rasid et al., 2018; Nazmi and Sarbon, 2019).

\subsubsection{Puncture test}

Puncture test is a measure of the resistance of the film to be perforated. When packed product has protuberances, the film should show good biaxial mechanical properties in order to maintain integrity. Puncture test was determined the force at the breaking point of the film. Table 2 shows the result of puncture force on the chicken skin gelatin film and chicken skin gelatin film blended with $\mathrm{CMC} /$ Centella asiatica extract. The addition of Centella considerably did not affect the puncture force of chicken skin gelatin film. The results suggest that the chain length of gelatin may determine the interactions between phenolic compounds in herb extracts and protein. Gelatin with higher chain length (without hydrolysis), more likely provided a more reactive group for interaction with phenolic compounds via hydrophobic interactions and hydrogen bonds, leading to film strengthening. As a result, the interconnection between gelatin molecules was more noticeable. This is similar to the findings of Kanatt et al. (2012) as results on puncture strength of chitosan-based film with and without extract were not significantly different ( $p>0.05)$. This result proved that the addition of Centella asiatica will maintain the puncture force and at the same time benefit other properties of chicken skin gelatin/CMC blended film.

\subsubsection{Water vapour permeability (WVP)}

The water vapour permeability (WVP) values of the blended films are important measures for the applications of packaging materials. Table 2 shows the WVP of control film and blended films incorporated with $0.3 \%$ and $0.7 \%$ Centella asiatica extract. Blended films with $0.3 \%$ and $0.7 \%$ Centella asiatica extract were not significantly higher in WVP value as compared to control film $(p>0.05)$. This was in the same agreement with Kanatt et al. (2012), which found that incorporation of plant extracts did not significantly $(\mathrm{p}>0.05)$ changed the WVP in bovine-hide gelatin films. The permeable characteristics of film were affected by the structural/ morphological characteristics of the polymeric matrix, the chemical nature of the macromolecule, the degree of cross-linking, and the chemical nature of the additives. The chemical nature of Centella aciatica did not significantly affect the cross-linking and polymetric matrix of the blended film. WVP value of film should be as low as possible since the main function of a food packaging is often to decrease moisture transfer between two components of a heterogeneous food product, or between the food and the surrounding atmosphere. This study found that the addition of Centella asiatica extract still will maintain the lower WVP value which is desirable in film packaging, besides improved other properties of the blended film. The WVP of composite films depends on the hydrophobic-hydrophilic ratio of the film constituents. High degrees of hydrogen bonding exhibit by highly polar polymers, resulting in elevated WVP values.

\subsubsection{Thermal properties of blended gelatin films} with Centella extracts

The melting temperature $\left(T_{m}\right)$ values of chicken skin gelatin/CMC blended film with Centella asiatica extract and control film were presented in Table 2. The addition of Centella asiatica extract to the blended film increased the $\mathrm{T}_{\mathrm{m}}$ value to a concentration of $0.3 \%$. However, the addition of Centella extract up to $0.7 \%$ had decreased the melting temperature. The chicken skin gelatin/CMC blended film with $0.3 \%$ Centella extract showed the highest $\mathrm{T}_{\mathrm{m}}$ value as compared to $0.7 \%$ extract and control film. In contrast, the transition enthalpy $(\Delta \mathrm{H})$ of blended film with $0.7 \%$ extract $(1.26 \mathrm{~J} / \mathrm{g})$ was the highest as compared to $0.3 \%$ extract $(0.63 \mathrm{~J} / \mathrm{g})$ and control $(0.10$ $\mathrm{J} / \mathrm{g})$. The higher melting point values for blended film of $0.3 \%$ Centella extract added indicated that cross-linking enhance by the presence of the phenolic compound in Centella extract and it might contribute to lower molecular mobility. These findings were supported by the TS value obtained in this study where the TS value of $0.7 \%$ extract added was lower than $0.3 \%$ extract added in the films. The higher melting point, due to the chain rigidity, may result from the phenolic compound and the intensity of both intermolecular and intramolecular interactions, including difficulty to internal rotation along the macromolecular chain. The melting point blended film of $0.7 \%$ extract shows significantly lower than blended film of $0.3 \%$ extract $(p<0.05)$. The reduction in melting point of film may be due to the increase of $\mathrm{OH}$ group in phenolic compound into film matrix as concentration of the centella extract was increased to $0.7 \%$. For transition enthalpy, the lowest enthalpy was found in the control film followed by $0.3 \%$ extract film and $0.7 \%$ extract film $(p<0.05)$.

\subsubsection{Light transmission and transparency}

Transparency and light transmission at selected wavelengths of all films are shown in Table 3. Light transmission of all films tested was insignificant at 200 $\mathrm{nm}$. In the UV range of $280 \mathrm{~nm}$, films added with Centella asiatica extract significantly exhibited low UV light transmission $(0.3 \%$ extract, $0.01 ; 0.7 \%$ extract, $0.02)$ compared to control film $(0.42)(p<0.05)$. Films with a lower UV light transmission value possess a good 
Table 3. Light transmission on chicken skin gelatin/CMC film incorporated with different concentration of Centella asiatica extract and chicken skin gelatin film/CMC (control film)

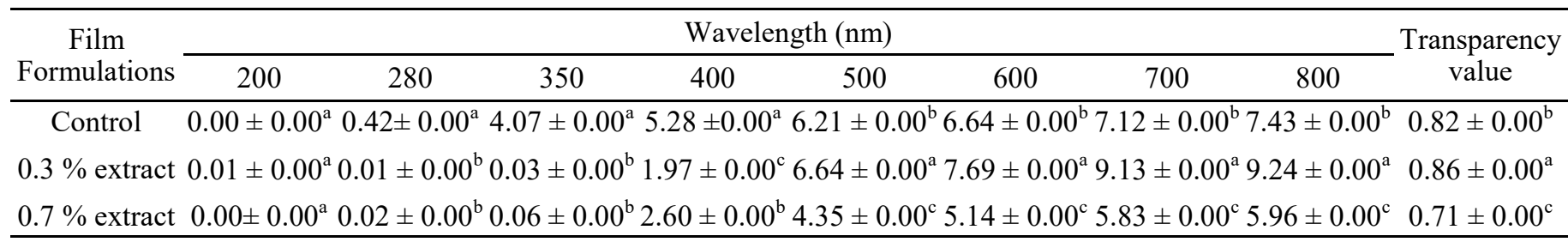

Different superscript within a column with different letters indicate significant difference $(p<0.05)$

barrier of UV penetration through the film. The alignment or arrangement of polymer in the film most likely governed the light transmission of film. Nonuniformities in the composition of the material of transparent material could cause significant changes in optical properties (Ahmad et al., 2012).

Transparency values of control film and blended films with Centella asiatica extract were presents in Table 3. The results show that the transparency value of blended film at $0.3 \%$ of Centella asiatica extract was the highest followed by control and blended film with $0.7 \%$ extract added. High transparency value indicated high film opacity, which improved light barrier properties. These findings are similar to a study by Suderman and Sarbon (2019), who found that increase of film opacity caused by incorporation of Centella asiatica extract, thereby improving the properties of the films as a light barrier. However, when the incorporation of Centella extract is increased into $0.7 \%$, the transparency value decreased, even lower than both control and $0.3 \%$ extract film. This might be probably due to properties of Centella asiatica which is hygroscopic thus increased the amount of water content in the film. The high amount of unbound water molecule inside the film matrices making light can penetrate through the film, thus reduced the opacity of films.

\subsection{Scanning electron microscopy (SEM) analysis}

Table 4 presents the cross section and surface morphology of blended film added with Centella asiatica extract and control film. For control film, the surface morphology of the film was fairly bumpy and rough. However, the film added with the extract showed a smooth and more homogeneous surface. This finding was similar to Tongnuanchan et al. (2012), in which films added with essential oils showed a smooth surface. This observation might due to the intermolecular interactions and entanglement between gelatin and extracts resulting in more homogenous surface. It also indicated that film forming solution had no collapse of emulsion occurred during dehydration due to the stable emulsion system of film forming solution (Tongnuanchan et al., 2012). The micrographs of cross section showed films blended with extract exhibited smooth matrix morphologies with a few cracks, and not much different as compared to the control film. However, for blended film with $0.7 \%$ extract, the crack was not so obvious as compared to other film. This indicates that the gelatin, glycerol and Centella extract mixed well in the film forming solution.

\subsection{X-Ray diffraction (XRD) analysis}

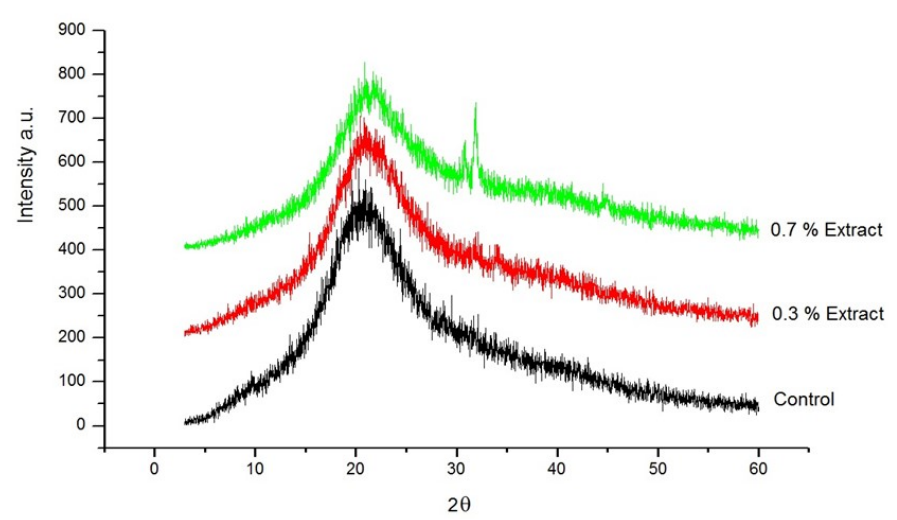

Figure 1. X-Ray Diffractogram of chicken skin gelatin/CMC film incorporated with different concentration of Centella asiatica extract and chicken skin gelatin film/CMC (control film).

X-ray diffraction (XRD) was used in order to investigate the crystallinity of structure and evaluate the compatibility of each material in blended film production (Nazmi et al., 2017). Figure 1 showed the diffractogram pattern of control and films with Centella asiatica extract. The diffractogram pattern showed peaks at $2 \theta=$ $20^{\circ}$ for all films. Diffractogram patterns were slightly similar for all film but with different intensities. The control film which showed stronger reflections at $20^{\circ}$, with higher intensity substantially compared to the intensity of the blended film with $0.3 \%$ and $0.7 \%$ Centella asiatica extract at same reflection area. Thus, the crystalline structure of gelatin/CMC blended film was progressively reduced by the addition of Centella asiatica extract, which means, it demonstrated a more amorphousness structure than the control film. Lack of re -crystallization during film production was the reason for the amorphous character of the films. This phase obtained may be due to the increase of moisture in the films contributed by Centella asiatica extract which is high hygroscopic properties, preventing the formation of semi-crystalline regions. The amourphous phase of the composite film implies that the hydrogen bonding 
Table 4. SEM micrographs of the surfaces and cross sections of chicken skin gelatin/CMC film incorporated with different concentration of Centella asiatica extract and chicken skin gelatin film/CMC (control film)

\begin{tabular}{|c|c|c|c|}
\hline Film & Control & $0.3 \%$ extract & $0.7 \%$ extract \\
\hline Surface & & & \\
\hline $\begin{array}{l}\text { Cross } \\
\text { section }\end{array}$ & & & \\
\hline
\end{tabular}

between gelatin and CMC and extract leads to their good compatibility. There is another peak observed at $2 \theta=30^{\circ}$ $-35^{\circ}$, of blended film with $0.3 \%$ and $0.7 \%$ Centella asiatica extract. The peak was obviously observed at diffractogram of film with $0.7 \%$ Centella asiatica extract as compared with $0.3 \%$ Centella asiatica extract, however, control film was not seen in diffractogram of control film. The appeared diffraction peak might show that with the addition of Centella asiatica extract to the film, the film was in a semi crystalline state. Thus, it may be concluded that increasing levels of Centella asiatica extract resulted in decreased crystallinity of blended film.

\section{Conclusion}

In conclusion, the antioxidant activity of chicken skin gelatin/CMC blended film increased with increasing amounts of extract. Centella asiatica addition into chicken skin gelatin/CMC blended film greatly increased their extensibility, transparency and tensile strength, while reduced UV- light penetration trough the blended films. Although the water vapour permeability of control film is lower than blended film with Centella asiatica extract, the existence of extract improved the thermal stability of the film. The addition of extract, however, decreases the crystallinity of the film, confirmed by XRD analysis. The effect and interactions of gelatin, glycerol, CMC and Centella asiatica extracts on the properties of active gelatin-based films show that extracts association on film greatly influenced the properties of the films blends.

\section{References}

Ahmad, M., Benjakul, S., Prodpran, T. and Winarni, T. (2012). Physico-mechanical and antimicrobial properties of gelatin film from the skin of unicorn leatherjacket incorporated with essential oils. Food Hydrocolloids, 28(1), 189-199. https:// doi.org/10.1016/j.foodhyd.2011.12.003

AOAC. (2006). Official methods of analysis of AOAC international $18^{\text {th }}$ ed. Virginia, USA:

Association of Official and Analytical Chemists International.

Cao, N., Fu, Y. and He, J. (2007). Preparation and physical properties of soy protein isolate and gelatin composite films. Food Hydrocolloids, 21(7), 11531162. https://doi.org/10.1016/j.foodhyd.2006.09.001

Cheow, C.S., Norizah, M.S., Kyaw, Z.Y. and Howell, N.K. (2007). Preparation and characterisation of gelatins from the skins of $\sin$ croaker (Johnius dussumieri) and shortfin scad (Decapterus macrosoma). Food Chemistry, 101(1), 386-391. https://doi.org/10.1016/j.foodchem.2006.01.046

Chew, K.K., Khoo, M.Z., Ng, S.Y., Thoo, Y.Y., Wan Aida, W.M. and Ho, C.W. (2011). Effect of ethanol concentration, extraction time and extraction temperature on the recovery of phenolic compounds and antioxidant capacity of Orthosiphon stamineus extracts. International Food Research Journal, 18 (4), 1427-1435.

Chiumarelli, M. and Hubinger, M.D. (2014). Evaluation of edible films and coatings formulated with cassava starch, glycerol, carnauba wax and stearic acid. Food Hydrocolloids, 38, 20-27. https://doi.org/10.1016/ j.foodhyd.2013.11.013

EÇA, K.S., Sartori, T. and Menegalli, F.C. (2014). Films and edible coatings containing antioxidants- a review. Brazilian Journal Food Technology, 17(2), 98-112. https://doi.org/10.1590/bjft.2014.017

Hong, S.I. and Krochta, J.M. (2006). Oxygen barrier 
performance of whey-protein-coated plastic films as affected by temperature, relative humidity, base film and protein type. Journal of Food Engineering, 77 (3), 739-745.

j.jfoodeng.2005.07.034

https://doi.org/10.1016/

Hoque, M.S., Benjakul, S. and Prodpran, T. (2011). Properties of film from cuttlefish (Sepia pharaonis) skin gelatin incorporated with cinnamon, clove and star anise extracts. Food Hydrocolloids, 25(5), 10851097. https://doi.org/10.1016/j.foodhyd.2010.10.005

Jahit, I.S., Nazmi, N.N.M., Isa, M.I.N. and Sarbon, N.M. (2016). Preparation and physical properties of gelatin/CMC/chitosan composite films as affected by drying temperature. International Food Research Journal, 23(3), 1068-1074.

Jridi, M., Hajji, S., Ayed, H., Ben Lassoued, I., Mbarek, A., Kammoun, M., Souissi, N. and Nasri, M. (2014). Physical, structural, antioxidant and antimicrobial properties of gelatin-chitosan composite edible films. International Journal of Biological Macromole, 67,373-379.

https://doi.org/10.1016/

j.ijbiomac.2014.03.054

Kanatt, S.R., Rao, M.S., Chawla, S.P. and Sharma, A. (2012). Active chitosan-polyvinyl alcohol films with natural extracts. Food Hydrocolloids, 29(2), 290 297. https://doi.org/10.1016/j.foodhyd.2012.03.005

Li, J.-H., Miao, J., Wu, J.-L., Chen, S.-F. and Zhang, Q.Q. (2014). Preparation and characterization of active gelatin-based films incorporated with natural antioxidants. Food Hydrocolloids, 37, 166-173. https://doi.org/10.1016/j.foodhyd.2013.10.015

Liu, F., Dai, R., Zhu, J. and Li, X. (2010). Optimizing color and lipid stability of beef patties with a mixture design incorporating with tea catechins, carnosine, and $\alpha$-tocopherol. Journal of Food Engineering, 98 (2), 170-177. https://doi.org/10.1016/ j.jfoodeng.2009.12.023

López-Mata, M.A., Ruiz-Cruz, S., Silva-Beltrán, N.P., Ornelas-Paz, J.D.J., Zamudio-Flores, P.B. and Burruel-Ibarra, S.E. (2013). Physicochemical, antimicrobial and antioxidant properties of chitosan films incorporated with carvacrol. Molecules, 18 (11), 13735-13753. https://doi.org/10.3390/ molecules 181113735

Moradi, M., Tajik, H., Razavi Rohani, S.M., Oromiehie, A.R., Malekinejad, H., Aliakbarlu, J. and Hadian, M. (2012). Characterization of antioxidant chitosan film incorporated with Zataria multiflora Boiss essential oil and grape seed extract. LWT - Food Science Technology, 46(2), 477-484. https://doi.org/10.1016/ j.lwt.2011.11.020

Nazmi, N.N., Isa, M.I.N. and Sarbon, N.M. (2017).
Preparation and characterization of chicken skin gelatin/CMC composite film as compared to bovine gelatin film. Food Bioscience, 19, 149-155. https:// doi.org/10.1016/j.fbio.2017.07.002

Nazmi, N.N.M. and Sarbon, N.M. (2019). Response surface methodology (RSM) on development and formulation optimization of chicken skin gelatin film blended with Carboxymethyl Cellulose (CMC) as affected by varying plasticizer concentrations. International Food Research Journal, 26(1), 47 57.

Nor, M.H.M., Nazmi, N.N.M., Isa, M.I.N. and Sarbon, N.M. (2017). Effects of plasticizer concentrations on functional properties of chicken skin gelatin films. International Food Research Journal, 24(5), 19101918.

Nur Hazirah, M.A.S.P., Isa, M.I.N. and Sarbon, N.M. (2016). Effect of xanthan gum on the physical and mechanical properties of chicken skin gelatin-CMC biodegradable blends films. Food Packaging and Shelf Life, 9, 55-63. https://doi.org/10.1016/ j.fps1.2016.05.008

Qi, X.-M., Liu, S.-Y., Chu, F.-B., Pang, S., Liang, Y.-R., Guan, Y., Peng, F. and Sun, R.-C. (2015). Preparation and Characterization of Blended Films from Quaternized Hemicelluloses and Carboxymethyl Cellulose. Materials, 9(1), 4. https:// doi.org/10.3390/ma9010004

Razali, A.N., Amin, A.M. and Sarbon, N.M. (2015). Antioxidant activity and functional properties of fractionated cobia skin gelatin hydrolysate at different molecular weight. International Food Research Journal, 22(2), 651-660.

Rasid, N.A.M., Nazmi, N.N.M., Isa, M.I.N. and Sarbon, N.M. (2018) Rheological, functional and antioxidant properties of films forming solution and active gelatin films incorporated with Centella asiatica (L.) urban extract. Food Packaging and Shelf life, 18, 115-124. https://doi.org/10.1016/j.fpsl.2018.10.002

Reihani, S.F.S. and Azhar, M.E. (2012). Antioxidant activity and total phenolic content in aqueous extracts of selected traditional Malay salads (Ulam). International Food Research Journal, 19(4), 1439-1444.

Rosli, N. and Sarbon, N.M. (2015). Physicochemical and structural properties of Asian swamp eel (Monopterus albus) skin gelatin as compared to bovine gelatin. International Food Research Journal, 22(2), 699-706.

Sarbon, N.M., Badii, F. and Howell, N.K. (2013). Preparation and characterisation of chicken skin gelatin as an alternative to mammalian gelatin. Food 
Hydrocolloids, 30(1), 143-151. https:// doi.org/10.1016/j.foodhyd.2012.05.009

Silva-Weiss, A., Bifani, V., Ihl, M., Sobral, P.J.A. and Gómez-Guillén, M.C. (2013). Structural properties of films and rheology of film-forming solutions based on chitosan and chitosan-starch blend enriched with murta leaf extract. Food Hydrocolloids, 31(2), 458-466. https://doi.org/10.1016/ j.foodhyd.2012.11.028

Simpson, B.K. (Ed.). (2012). Food Biochemistry and Food Processing. USA: John Wiley and Sons.

Singh, S., Singh, D.R., Banu, V.S. and Avinash, N. (2014). Functional constituents (micronutrients and phytochemicals) and antioxidant activity of Centella asiatica (L.) Urban leaves. Industrial Crops and Products, 61, 115-119. https://doi.org/10.1016/ j.indcrop.2014.06.045

Siripatrawan, U. and Harte, B.R. (2010). Physical properties and antioxidant activity of an active film from chitosan incorporated with green tea extract. Food Hydrocolloids, 24(8), 770-775. https:// doi.org/10.1016/j.foodhyd.2010.04.003

Suderman, N. and Sarbon, N.M. (2019). Preparation and characterization of gelatin-based films with the incorporation of Centella asiatica (L.) urban extract. Food Research, 3(5), 506-514. https:// doi.org/10.26656/fr.2017.3(5).045

Tongnuanchan, P., Benjakul, S. and Prodpran, T. (2012). Properties and antioxidant activity of fish skin gelatin film incorporated with citrus essential oils. Food Chemistry, 134(3), 1571-1579. https:// doi.org/10.1016/j.foodchem.2012.03.094

Yingyuad, S., Ruamsin, S., Reekprkhon, D., Douglas, S., Pongamphai, S. and Siripatrawan, U. (2006). Effect of chitosan coating and vacuum packaging on the quality of refrigerated grilled pork. Packaging Technology Science, 19(3), 149-157. https:// doi.org/10.1002/pts.717

Zainol, M.K., Abd Hamid, A., Yusof, S. and Muse, R. (2003). Antioxidative activity and total phenolic compounds of leaf, root and petiole of four accessions of Centella asiatica (L.) Urban. Food Chemistry, 81(4), 575-581. https://doi.org/10.1016/ S0308-8146(02)00498-3 